\title{
The pan-deacetylase inhibitor panobinostat affects angiogenesis in hepatocellular carcinoma models via modulation of CTGF expression
}

\author{
SUSANNE GAHR ${ }^{1-3}$, CHRISTIAN MAYR $^{4,5}$, TOBIAS KIESSLICH ${ }^{4,5}$, ROMANA ILLIG $^{6}$, DANIEL NEUREITER ${ }^{6}$, \\ BEATE ALINGER $^{6}$, MARION GANSLMAYER ${ }^{1}$, TILL WISSNIOWSKI ${ }^{1,7}$, PIETRO DI FAZIO ${ }^{8}$, \\ ROBERTA MONTALBANO $^{8}$, JOACHIM H. FICKER ${ }^{2,3}$, MATTHIAS OCKER $^{1,8,10}$ and KARL QUINT ${ }^{1,8,9}$ \\ ${ }^{1}$ Department of Medicine 1, University Hospital Erlangen, Erlangen; ${ }^{2}$ Klinikum Nuernberg, \\ Department of Respiratory Medicine, Allergology and Sleep Medicine, Nuremberg; ${ }^{3}$ Paracelsus Medical University Nuernberg, \\ Nuremberg, Germany; ${ }^{4}$ Laboratory for Tumour Biology and Experimental Therapies, Paracelsus Medical University, Salzburg; \\ ${ }^{5}$ Department of Internal Medicine I, Salzburger Landeskliniken (SALK)/Paracelsus Medical University, Salzburg; \\ ${ }^{6}$ Institute of Pathology, Salzburger Landeskliniken, Paracelsus Private Medical University, Salzburg, Austria; \\ ${ }^{7}$ Department of Gastroenterology and Endocrinology, University Hospital, Phillips University, Marburg; ${ }^{8}$ Institute for Surgical \\ Research, Phillips University Marburg, Marburg; ${ }^{9}$ Institute of Pathology, University Hospital Erlangen, Erlangen, Germany
}

Received May 4, 2015; Accepted June 8, 2015

DOI: 10.3892/ijo.2015.3087

\begin{abstract}
Post-translational modifications of chromatin components are significantly involved in the regulation of tumor suppressor gene and oncogene expression. Connective tissue growth factor (CTGF) is an epigenetically regulated growth factor with functions in angiogenesis and cell-matrix interactions and plays a pivotal role in hepatocellular carcinoma (HCC). The pharmacologic inhibition of histone and protein deacetylases represents a new approach to interfere with pathways of apoptosis and angiogenesis. We investigated the effect of the pan-deacetylase inhibitor panobinostat (LBH589) on human HCC cell lines HepG2 (p53wt) and Hep3B (p53null) and in a subcutaneous xenograft model and explored the influence on angiogenesis. Specimens were characterized by quantitative real-time PCR. Protein was separated for western blotting against CTGF, VEGF, VEGF receptor-1 (VEGFR-1/FLT-1), VEGF receptor-2 (VEGFR-2/KDR), MAPK and phospho-MAPK. In vivo, HepG2 cells were xenografted to NMRI mice and treated with daily i.p. injections of $10 \mathrm{mg} / \mathrm{kg}$ panobinostat. After 1,7 and 28 days, real-time
\end{abstract}

Correspondence to: Dr Susanne Gahr, Klinikum Nuernberg, Department of Respiratory Medicine, Allergology and Sleep Medicine, Prof.-Ernst-Nathan-Strasse 1, D-90419 Nuremberg, Germany E-mail: susanne.gahr@klinikum-nuernberg.de

Present address: ${ }^{10}$ Bayer Pharma AG, Experimental Medicine Oncology, Berlin, Germany

Key words: hepatocellular carcinoma, histone deacetylases, histone deacetylase inhibitor, LBH589, panobinostat, connective tissue growth factor, vascular endothelial growth factor, FLT-1, KDR, antiangiogenesis
PCR was performed. Immunohistochemistry and western blotting were examined after 28 days. An increased significant expression of CTGF was only seen after $24 \mathrm{~h}$ treatment with $0.1 \mu \mathrm{M}$ panobinostat in HepG2 cells and Hep3B cells, whereas after $72 \mathrm{~h}$ treatment CTGF expression clearly decreased. In the xenografts, treatment with panobinostat showed a minimal CTGF expression after 1 day and 4 weeks, respectively. In vitro as well as in vivo, VEGF was not affected by panobinostat treatment at any time. In conclusion, panobinostat influences extracellular signaling cascades via CTGF-dependent pathways.

\section{Introduction}

Hepatocellular carcinoma (HCC) is one of the most common cancers worldwide and the third leading cause of cancerrelated death (1-4). Major risk factors for HCC development are cirrhosis with underlying chronic viral hepatitis, alcoholic liver disease and non-alcoholic steatohepatitis. Despite the introduction of targeted therapies like the multi-kinase inhibitor sorafenib, treatment with curative intention is still limited with unsatisfactory overall survival results (5-9).

A prerequisite for the growth and spread of malignant solid tumors is the formation of new blood vessels to provide oxygen and nutrient supply to the mass of tumor cells (10). Angiogenesis is a highly complex process involving various growth factors such as vascular endothelial growth factor (VEGF), growth factor receptors like fms-like tyrosine kinase-1 (FLT-1; VEGF receptor-1) or kinase insert domain containing receptor (KDR; VEGF receptor-2) as well as extracellular matrix components like matrix metalloproteinases, inflammatory cells including macrophages and intracellular signaling pathways such as the Hif-1 $\alpha$ cascade (11-13). VEGF is an extracellular signaling molecule stimulating proliferation 
and migration of endothelial (progenitor) cells and regulates the permeability of blood vessels via activating a family of transmembrane tyrosine kinase receptors (14-17). FLT-1 and especially KDR are the central mediators of VEGF signaling in angiogenesis and have been shown to be commonly overexpressed in malignant tumors, including $\mathrm{HCC}$, and their overexpression is associated with limited overall survival of patients (18-22). Although various anti-angiogenic compounds like the multi-kinase inhibitor sorafenib and the monoclonal anti-VEGF antibody bevacizumab have been used for the therapy of HCC, the overall efficacy of anti-angiogenic treatments is still disappointing and these treatments are associated with considerable side effects (23-25).

The role of the surrounding stroma as well as inflammatory cells has recently been recognized as a key feature of tumor-driven angiogenesis $(26,27)$. Connective tissue growth factor (CTGF), also known as CCN2, is a 38-kDa protein and was originally identified as a growth factor secreted by human vascular endothelial cells (28). It is a multifunctional signaling modulator involved in several physiologic and pathologic processes such as fibrosis in kidneys and skin, osteogenesis, angiogenesis and tumor development (29-33). In HCC, CTGF has been shown to contribute to tumor growth in an autocrine loop and its overexpression is negatively correlated with overall survival (34-38). Previously, we have shown that the expression of CTGF can be modulated by the histone deacetylase inhibitor (HDACi) Trichostatin A (TSA) (39).

HDACi are currently evaluated as anticancer agents for various hematologic and solid malignancies (40). Panobinostat (LBH589) represents a novel pan-deacetylase inhibitor that has shown excellent efficacy against HCC growth alone or combined in preclinical models and early clinical trials (41-44). Besides their classical mode of action as transcriptional regulators, HDACi are now considered to interfere with a variety of other cellular pathways like cytosolic protein stabilization and signaling pathways, including angiogenesis-related signaling (45-47).

We therefore investigated if and to what extent the pandeacetylase inhibitor panobinostat mediates its anti-angiogenic properties via regulation of the CTGF signaling pathway in HCC cell lines and in a subcutaneous xenograft model in vivo. Our study shows that panobinostat leads to a significant growth delay with prolonged overall survival, mediated by reduced tumor cell proliferation, increased apoptosis and reduced angiogenesis in tumor xenografts (41).

\section{Materials and methods}

Cell culture. The human hepatoma cell lines HepG2 (p53wt) and Hep3B (p53null) were obtained from the German collection of microorganisms and cell cultures (DSMZ, Braunschweig, Germany) and maintained under standard conditions as described previously (41). Panobinostat (LBH589) was provided by Novartis Pharma AG (Basel, Switzerland) and was prepared as previously described $(41,45)$. For all in vitro experiments, 300,000 cells were seeded to 6-well tissue culture plates (Becton-Dickinson, Heidelberg, Germany) $24 \mathrm{~h}$ before treatment. Cells were treated with LBH589 at 0.1 and $0.01 \mu \mathrm{M}$ dissolved in complete growth medium. The medium was not changed during the experiments.
HepG2 xenograft samples. Samples from previously established xenografts of HepG2 cells to male athymic nu/nu NMRI mice were used for this study (41).

Protein isolation and western blotting. Total protein content was isolated after centrifuging hepatoma cells at 1,000 rpm for $10 \mathrm{~min}$, discarding the liquid phase and adding $50 \mu \mathrm{l}$ of Jie's protein lysis buffer, consisting of $10 \mathrm{mM} \mathrm{NaCl}_{2}, 0.5 \% \mathrm{NP}-40$, $20 \mathrm{mM}$ Tris- $\mathrm{HCl} \mathrm{pH} 7.4,5 \mathrm{mM} \mathrm{MgCl}{ }_{2}, 10 \mu \mathrm{g} / \mathrm{ml}$ Prot-I, $1 \mathrm{mM}$ PMSF. After $30 \mathrm{~min}$ cooling on ice with intermediate vortexing, the suspension was divided into two portions and stored at $-80^{\circ} \mathrm{C}$. Samples were subjected to 6-14\% SDS-PAGE (Invitrogen, Carlsbad, CA, USA), transferred to a nitrocellulose membrane and blocked for $1 \mathrm{~h}$ at room temperature in a TBS or PBS buffer containing 0.1\% Tween-20 and 5\% low fat milk powder. Membranes were incubated overnight with primary antibodies against CTGF (1:500), VEGF $(1: 1,000)$, FLT-1 (1:1,000) (all from Abcam, Cambridge, UK), KDR (1:1,000; Merck Millipore, Darmstadt, Germany), MAPK $(1: 1,000)$ and p-MAPK $(1: 1,000)$ (both from Cell Signaling Technology, Danvers, MA, USA). Membranes were incubated with a peroxidase coupled secondary antibody $(1: 2,000$, antimouse or anti-rabbit IgG; Pierce, Rockford, IL, USA) for $1 \mathrm{~h}$ at room temperature (RT). Reactive bands were detected with the ECL chemiluminescnce reagent (Amersham Pharmacia Biotech, Freiburg, Germany) and analyzed using GelScan 5 software (BioSciTec, Frankfurt, Germany). Signals were standardized to $\beta$-actin (1:5,000; Sigma-Aldrich, Taufkirchen, Germany) content of each sample.

Densitometric quantification of the western blot analyses was done using Bio 1D (Vilber Lourmat, Eberhardzell, Germany) and normalized to untreated controls and $\beta$-actin as the loading control.

Quantitative real-time PCR. Treated cells and controls were harvested for qPCR after 24-72 h using TRizol ${ }^{\circledR}$ (Ambion/Life Technologies, Vienna, Austria) and total RNA extracted using Direct-zol RNA MiniPrep kit (Zymo Research, Irvine, CA, USA). cDNA was synthetized with 0.15 to $0.35 \mu \mathrm{g}$ RNA using the GoScript ${ }^{\mathrm{TM}}$ Reverse Transcription System (Promega, Mannheim, Germany). Finally, real-time PCR was performed with GoTaq ${ }^{\circledR}$ qPCR Master Mix (Promega) on a ViiA7 real-time PCR system (Applied Biosystems/Life Technologies) using the following primers (all from Qiagen, Hilden, Germany): $\beta$-actin [internal control/reference gene, Qiagen cat. no. QT01680476), VEGF (QT01682072), FLT-1/ VEGFR-1 (QT00073640), KDR/VEGFR-2 (QT00069818) and CTGF1 (QT00052899)]. All procedures were performed according to the respective user manuals. Specific amplification was verified using melt curves and gene expression calculated using the $\Delta \Delta \mathrm{Ct}$ method (48). Gene expression levels are presented as mean expression relative to their untreated controls \pm standard error of the mean (SEM).

Immunohistohemistry (IHC). Antigen retrieval was performed by heat induced epitope retrieval in $\mathrm{pH} 9.0$ antigen retrieval buffer (Dako, Glostrup, Denmark) at $95^{\circ} \mathrm{C}$ for $60 \mathrm{~min}$. Endogenous peroxidase blocking was carried out for $10 \mathrm{~min}$ with peroxidase blocking reagent (Dako). Subsequently, primary antibody against CTGF (1:50; Abcam) was applied for $30 \mathrm{~min}$ at 
A

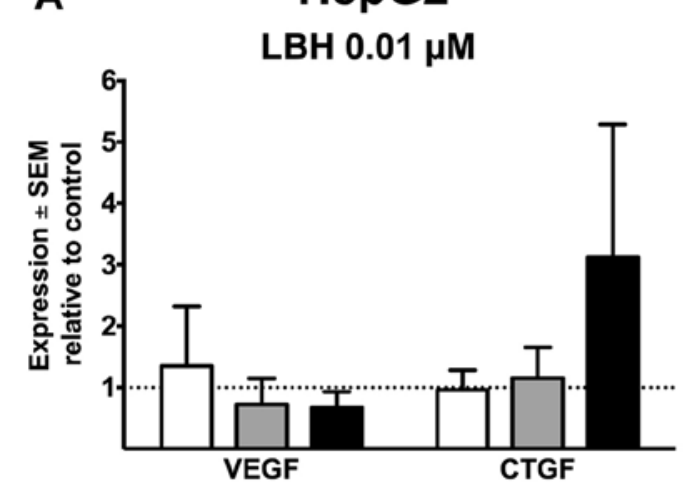

B

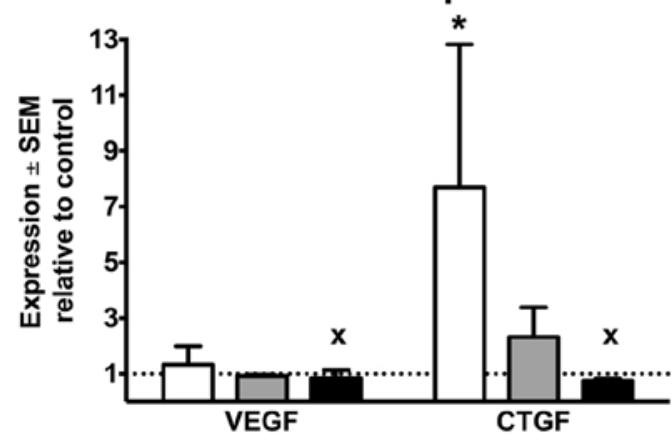

C

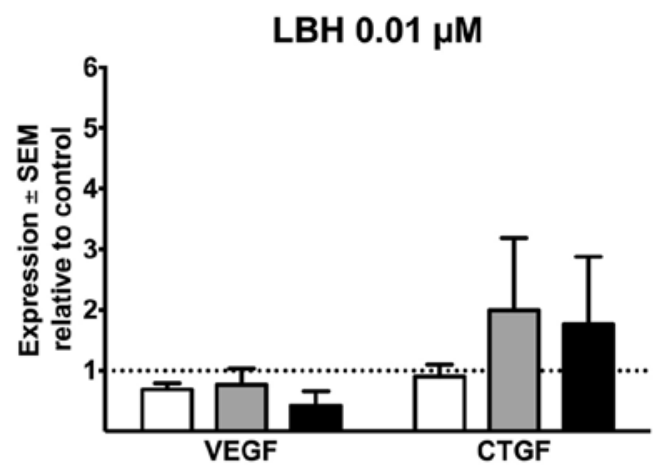

D

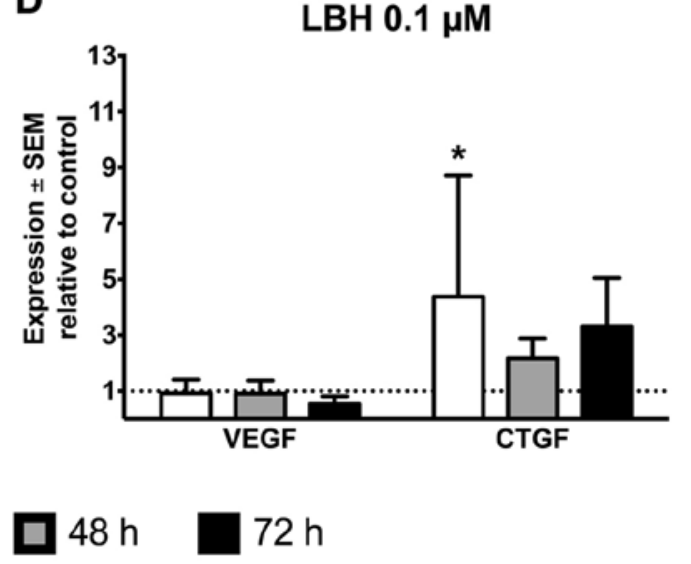

Figure 1. Effect of panobinostat (LBH589) on gene expression of connective tissue growth factor (CTGF), vascular endothelial growth factor (VEGF) and fms-like tyrosine kinase-1 (FLT-1) in vitro in HepG2 and Hep3B cells. (A) Quantitative real-time RT-PCR analysis after 24, 48 and 72 h treatment with $0.01 \mu \mathrm{M}$ panobinostat (A) and $0.1 \mu \mathrm{M}$ panobinostat (B) in HepG2 cells, with $0.01 \mu \mathrm{M}$ panobinostat (C) and $0.1 \mu \mathrm{M}$ panobinostat (D) in Hep3B cells. Gene expression was normalized to $\beta$-actin and expressed relative to untreated controls (set at 1.0). Asterisks indicate statistically significant differences in gene expression vs. the untreated controls $(\mathrm{p}<0.01)$. The symbol $(\mathrm{x})$ indicates that very few viable cells remained after $72 \mathrm{~h}$ of treatment in these cells.

RT and detected using the EnVision Detection system (Dako). Visualisation was performed using diaminobenzidine (DAB) as the chromogen substrate (Roche Molecular Biochemicals, Mannheim, Germany), all according to the manufacturers' instructions. Slides were counterstained with hematoxylin.

Statistical analysis and scientific graphing. Significant differences in qPCR gene expression were calculated using the t-test for paired samples and corrected for multiple comparisons using the Holm-Sidak post-hoc test. $\mathrm{P}<0.05$ was regarded as statistically significant. Statistics and scientific graphing were performed using Prism 6 (GraphPad Software Inc., La Jolla, CA, USA).

\section{Results}

In vitro experiments. Treatment of the p53-wild-type HepG2 cell line with $0.1 \mu \mathrm{M}$ panobinostat induced a strong increase of CTGF mRNA expression to 7.7-fold after only $24 \mathrm{~h}$ and values dropped to 2.3 -fold after $48 \mathrm{~h}$. At $72 \mathrm{~h}$, treatment with panobinostat led to a drastic reduction of cells numbers, thus very few viable cells were left for analysis, even after repeated experiments, and these cells expressed CTGF 0.8-fold compared to the untreated controls (Fig. 1A and B). VEGF was induced 1.3-fold after $24 \mathrm{~h}$, and levels after 48 and $72 \mathrm{~h}$ dropped to 0.9 - and 0.8 -fold, respectively. At $0.01 \mu \mathrm{M}$, a less dramatic change in gene expression was observed: VEGF was upregulated to 1.3-fold at $24 \mathrm{~h}$, and dropped (in a similar fashion as in $0.1 \mu \mathrm{M}$ treated cells) to 0.7 - and 0.6 -fold at 48 and $72 \mathrm{~h}$. At this lower concentration, CTGF was gradually induced 1.0-, 1.2- and 3.1-fold at 24, 48 and $72 \mathrm{~h}$, respectively. The gradual timedependent CTGF induction at $0.01 \mu \mathrm{M}$ in the HepG2 cells was paralleled by a strong induction at $24 \mathrm{~h}$ at $0.1 \mu \mathrm{M}$ followed by a drop of CTGF in the remaining viable cells at 48 and $72 \mathrm{~h}$ at this higher concentration.

The clear time- and dose-dependent change in gene expression seen in the p53-wild-type HepG2 cells was not observable in the p53-deficient Hep3B cells. VEGF expression remained at 0.9 -fold of untreated controls at 24 and $48 \mathrm{~h}$ and dropped to 0.5 -fold after $72 \mathrm{~h}$ incubation with $0.1 \mu \mathrm{M}$ panobinostat. At the lower concentration of $0.01 \mu \mathrm{M}$ LBH, VEGF ranged between 0.7- and 0.4-fold during the treatment period. However, CTGF was induced 4.4-, 2.2- and 3.3-fold after 24, 48 and $72 \mathrm{~h}$ incubation with $0.1 \mu \mathrm{M}$ panobinostat (and to only 0.9-, 2.0- and 1.8-fold under $0.01 \mu \mathrm{M}$ panobinostat) (Fig. 1C and D). FLT-1 was not expressed in vitro at any time-point in the HepG2 and Hep3B cells.

In western blot analysis, we could not detect VEGF expression in HepG 2 cells and neither cell line expressed FLT-1 on protein level (Fig. 2). VEGF in Hep3B cells was induced at 

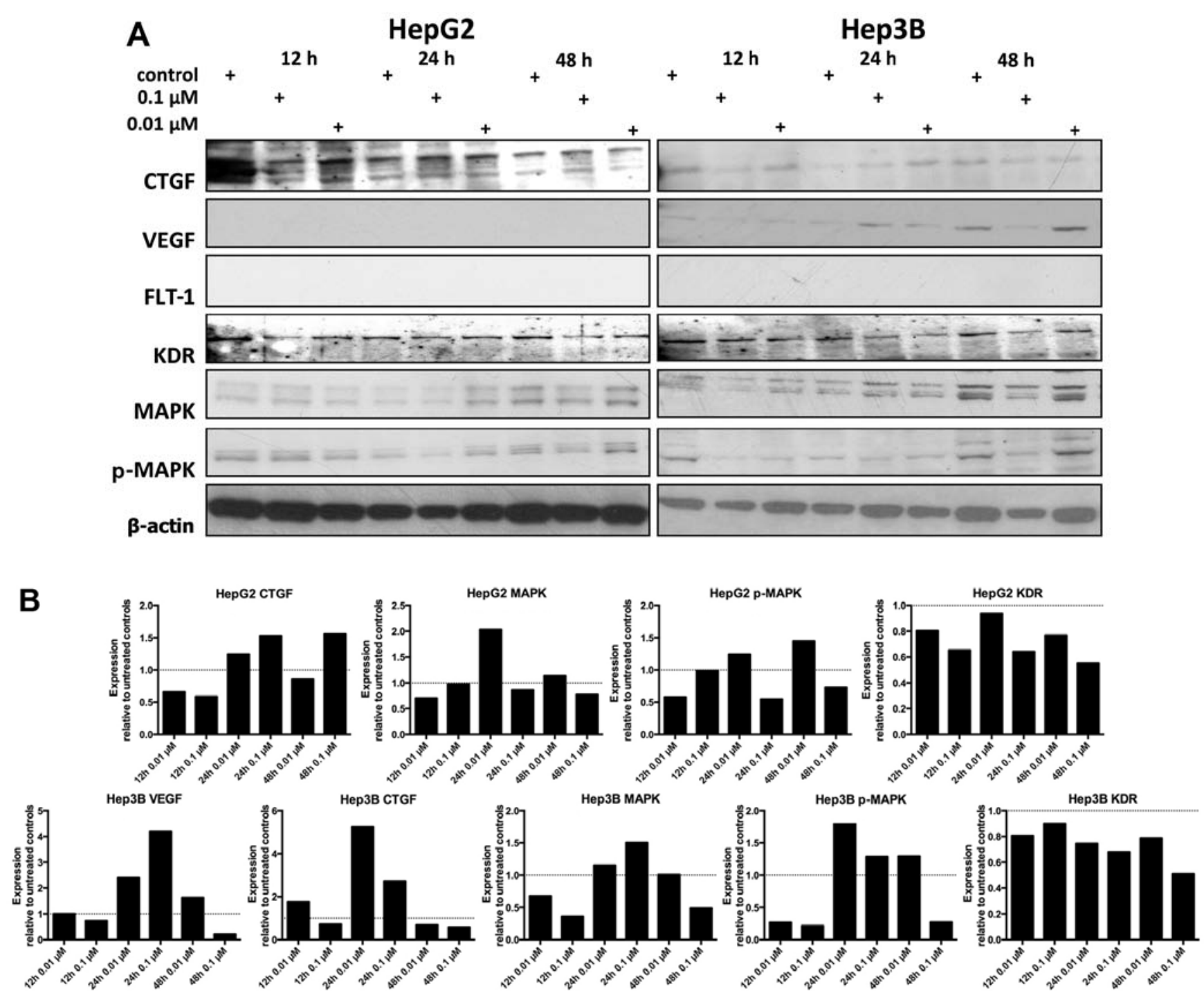

Figure 2. Western blot analysis of expression of connective tissue growth factor (CTGF), vascular endothelial growth factor (VEGF), fms-like tyrosine kinase-1 (FLT-1), kinase insert domain containing receptor (KDR), MAPK, p-MAPK in vitro and densitometric quantification. HepG2 and Hep3B cells were incubated with 0.1 and $0.01 \mu \mathrm{M}$ panobinostat for 12, 24 and $48 \mathrm{~h}$. Western blot results show representative examples for expression of CTGF, VEGF, FLT-1, KDR, MAPK and p-MAPK as well as $\beta$-actin, which served as loading control (A). Protein expression analyzed using western blot analysis was quantified by densitometry (B). Shown are expression values for CTGF, MAPK, p-MAPK, KDR and VEGF after treatment of HepG2 and Hep3B cell lines with 0.01 and $0.1 \mu \mathrm{M}$ of panobinostat for $12-48 \mathrm{~h}$.

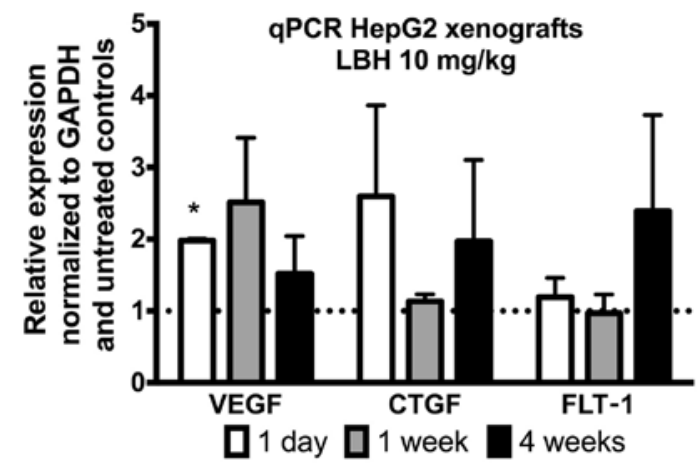

Figure 3. Effect of panobinostat (LBH589) on gene expression of connective tissue growth factor (CTGF), vascular endothelial growth factor (VEGF) and fms-like tyrosine kinase-1 (FLT-1) in vivo. HepG2 xenograft specimens were analyzed for mRNA expression of CTGF, VEGF and FLT-1 after 1, 7 and 28 days of daily i.p. injections of $10 \mathrm{mg} / \mathrm{kg}$ panobinostat. Results were normalized to $\beta$-actin content of each sample and represent mean \pm SD of 8 independent samples per group and are expressed relative to expression levels of untreated control animals set at 1.0 for each time-point.
$24 \mathrm{~h}$ by panobinostat $2.4-$ and 4.2 -fold at concentrations of 0.01 and $0.1 \mu \mathrm{M}$, respectively, as calculated by densitometry. Longer incubation (48 h) reduced VEGF expression to 1.6and 0.2 -fold at 0.01 and $0.1 \mu \mathrm{M}$. CTGF was induced most effectively in HepG2 cells by $0.1 \mu \mathrm{M}$ panobinostat at either 24 or $48 \mathrm{~h}$ to levels of 1.5- and 1.6-fold, respectively. In Hep3B cells, $24 \mathrm{~h}$ incubation induced CTGF most prominently, but the lower dose of $0.01 \mu \mathrm{M}$ was more effective than $0.1 \mu \mathrm{M}$ and the CTGF levels were 5.3- and 2.7-fold elevated in this setting. In both cell lines, elevated levels of MAPK were accompanied by elevated levels of p-MAPK and vice versa. The two highest levels of MAPK in HepG2 (2.0-fold at $24 \mathrm{~h}$ $0.01 \mu \mathrm{M}$ and 1.1-fold at $48 \mathrm{~h} 0.01 \mu \mathrm{M})$ were accompanied by the two highest levels of p-MAPK (1.2-fold at $24 \mathrm{~h} 0.01 \mu \mathrm{M}$ and 1.4-fold at $48 \mathrm{~h} 0.01 \mu \mathrm{M}$ ), resulting in a MAPK/p-MAPK ratio of 1.67 and 0.79 at 24 and $48 \mathrm{~h}$ for $0.01 \mu \mathrm{M}$. At all other time-points and concentrations, MAPK and p-MAPK were suppressed compared to the untreated controls. The lowest 


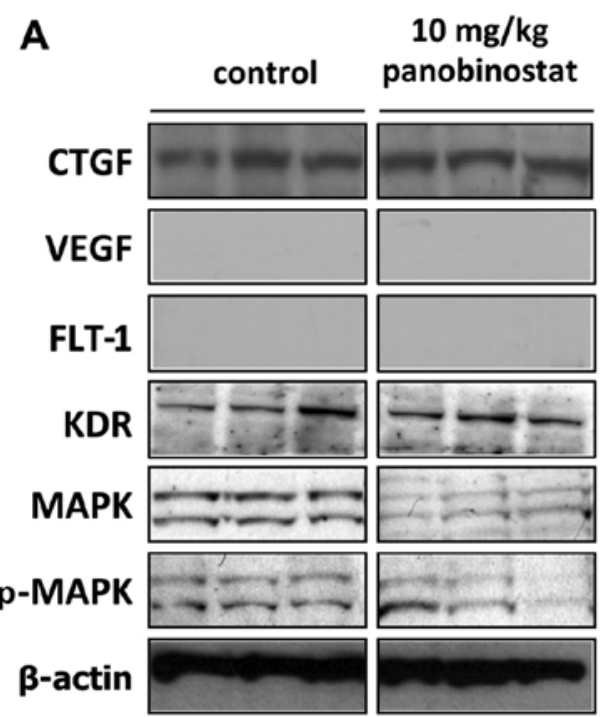

\section{B \\ HepG2 xenografts 4 weeks densitometry}

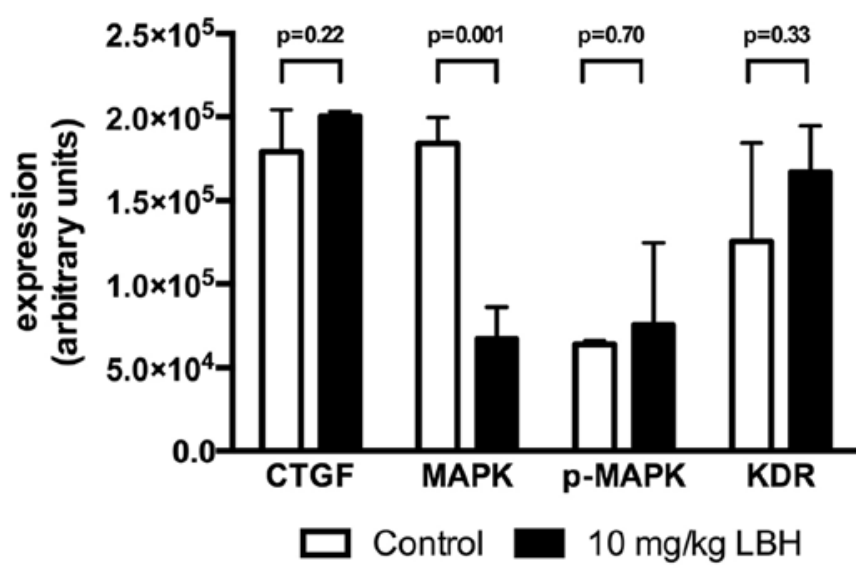

\section{relative expression}

\begin{tabular}{|l|r|r|r|c|}
\hline & \multicolumn{2}{|c|}{ Control } & \multicolumn{2}{c|}{$10 \mathrm{mg} / \mathrm{kg}$ LBH } \\
\hline & Mean & \multicolumn{1}{c|}{ SD } & Mean & \multicolumn{1}{c|}{ SD } \\
\hline CTGF & 1.00 & 0.14 & 1.12 & 0.02 \\
\hline MAPK & 1.00 & 0.08 & 0.36 & 0.10 \\
\hline p-MAPK & 1.00 & 0.03 & 1.18 & 0.77 \\
\hline KDR & 1.00 & 0.47 & 1.33 & 0.22 \\
\hline
\end{tabular}

Figure 4. Western blot analysis of expression of connective tissue growth factor (CTGF), vascular endothelial growth factor (VEGF), fms-like tyrosine kinase-1 (FLT-1), kinase insert domain containing receptor (KDR), MAPK, p-MAPK and densitometric analysis of protein expression in vivo. Western blot analysis of representative HepG2 xenograft specimens from untreated controls or animals receiving $10 \mathrm{mg} / \mathrm{kg}$ panobinostat. Tumor samples were obtained at the end of the treatment period and subjected to semiquantitative western blotting against CTGF, VEGF, FLT-1, KDR, MAPK and p-MAPK. $\beta$-actin served as a loading control (A). Protein expression was quantified by densitometry. Shown are expression values for CTGF, MAPK, p-MAPK, KDR and after treatment of HepG2 xenograft specimens treated with $10 \mathrm{mg} / \mathrm{kg}$ panobinostat for 4 weeks (B).

expression in HepG2 was thus observed at $12 \mathrm{~h} 0.01 \mu \mathrm{M}$ for both MAPK (0.7-fold) and p-MAPK (0.6-fold) (ratio MAPK/ p-MAPK, 1.17) and in Hep3B at $12 \mathrm{~h} 0.1 \mu \mathrm{M}$ also for both MAPK (0.4-fold) and p-MAPK (0.2-fold) (ratio 2). KDR levels were generally suppressed at all time-points and concentrations, with the lowest level of 0.55-fold in HepG2 and 0.51-fold in Hep3B (vs. untreated controls) at $48 \mathrm{~h} 0.1 \mu \mathrm{M}$ in both cell lines.

HepG2 xenografted nude mice. Treatment of nude mice bearing HepG2 xenografts with daily i.p. injections of $10 \mathrm{mg} / \mathrm{kg}$ panobinostat resulted in an increase of VEGF on mRNA level 2.0-, 2.5- and 1.5-fold after 1 day, 1 week and 4 weeks, respectively (Fig. 3). CTGF was upregulated 2.6-, 1.1- and 2.0-fold while FLT-1 reached an expression of 1.2-, 1.0- and 2.4-fold in treated vs. the untreated mice. After 4 weeks of treatment of the HepG2 xenografts in the nude mice, the western blot analysis revealed an relative expression change of CTGF (1.1-fold, vs. untreated xenografts), p-MAPK (1.2-fold) and KDR (1.3-fold) and a downregulation of MAPK to 0.4 -fold ( $\mathrm{p}=0.001$ ) of untreated controls (Fig. 4).

In immunohistochemical staining of the explanted xenografts after 4 weeks (Fig. 5), the $10 \mathrm{mg} / \mathrm{kg}$ panobinostat treated samples showed an expression of CTGF [low (Fig. 5A), moderate (Fig. 5B)] in contrast to $2.5 \mathrm{mg}$ panobinostat treated samples (Fig. 5C) and untreated controls (Fig. 5D).

\section{Discussion}

In the present study we investigated the anti-angiogenic properties of the pan-deacetylase inhibitor panobinostat via regulation of the CTGF signaling pathway in HCC cell lines and a subcutaneous xenograft model in vivo.

Panobinostat (LBH589) plays an important role in anti-angiogenesis (45). Recently, Di Fazio et al showed a panobinostat-mediated significant growth delay of a subcutaneous HCC xenograft model with prolonged overall survival, mediated by reduced tumor cell proliferation, increased apoptosis and especially reduced angiogenesis (41). As key message of this study, panobinostat induces alternative apoptotic pathways dependent on the p53 status. Furthermore, it was shown macroscopically that the microvascular density and tumor size of panobinostat treated HCC xenografts were significantly decreased.

Our results show that panobinostat induces a contextdependent differential expression of CTGF in vitro and in vivo in a subcutaneous xenograft model after daily i.p. injections of $10 \mathrm{mg} / \mathrm{kg}$ panobinostat. The previously shown tumor growth inhibition (41) was associated with the inhibition of the MAPK signaling pathway and with inhibition of tumor vascularization. For this study, in vivo samples from those previous experiments (41) were used. Interestingly, the protein levels of CTGF in the western blot analyses were downregulated, while the 

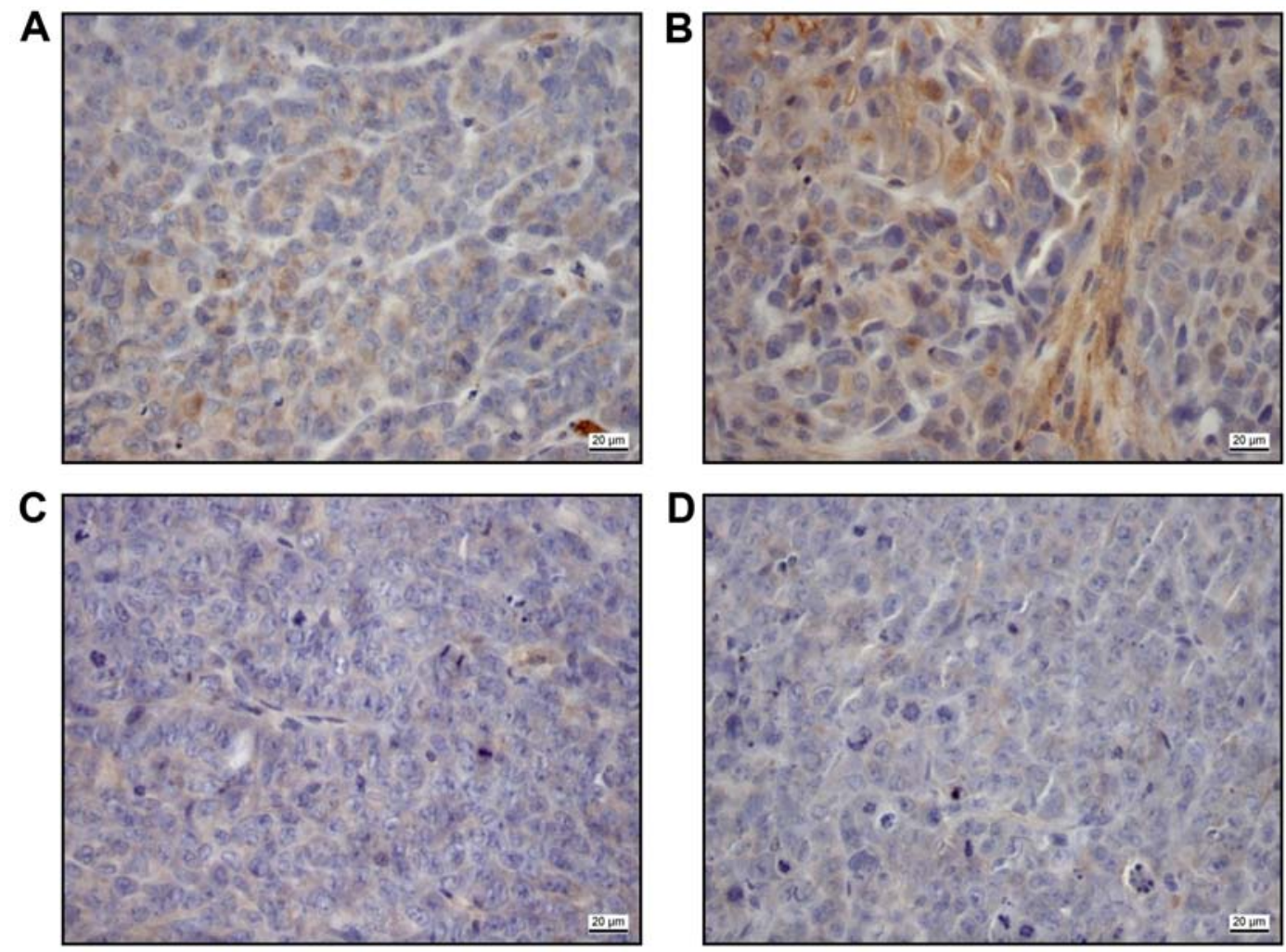

Figure 5. Immunohistochemical analysis of connective tissue growth factor (CTGF) expression (magnification, x400). HepG2 xenografts were treated with daily i.p. injections of $10 \mathrm{mg} / \mathrm{kg}$ panobinostat for 28 days. Panobinostat treated samples (10 mg/kg) showed an expression of CTGF [low (A), moderate (B)] in contrast to $2.5 \mathrm{mg}$ panobinostat treated samples (C) and untreated controls (D) (inset control tissue of liver cirrhosis).

mRNA expression of CTGF in HepG2 and Hep3B cells after 24 and $48 \mathrm{~h}$ were mainly upregulated. An increased expression of CTGF was also seen in the immunohistochemical analysis of panobinostat treated xenograft samples. Because CTGF can be both secreted and membrane bound, western blot analysis of the cell lysate may not reflect the total protein amount produced when compared to mRNA expression. While in mesangial cells it is bound to the cell surface (49), it has been shown that in hepatocellular carcinoma cells, a fraction of the produced protein remains cell-bound (38). This may explain why our mRNA and protein expression data do not necessarily correlate. One other reason may be that the CTGF mRNA pool does not necessarily translate into a 1:1 expression on the protein level. A further reason could be the fact that in the in vivo xenograft model, the CTGF expression is especially triggered by endothelial cells. This assumption is supported by findings of Komorowsky et al (39): treatment of cultured endothelial cells with different HDAC inhibitors upregulated CTGF mRNA and protein. Their data indicate that the effect of HDAC inhibitors on CTGF expression is largely cell dependent in non-tumor cells.

In this study VEGF and FLT-1 (VEGFR-1) are not expressed and thus do not seem to play a role in treatment with panobinostat, especially in the xenograft model. VEGF and the VEGFR system are known to be main regulators of angiogenesis. In this study there is absolutely no expression of VEGF and FLT-1, especially in the controls of the xenograft samples. It could be speculated that an alternative angiogenesis pathway is activated in this xenograft model involving the xenograft environment (50), especially because KDR (VEGFR-2) is expressed and induced in the xenografts after treatment.

Panobinostat is a pan-deacetylase inhibitor and, like many other compounds targeting histone deacetylases, a promising drug against different malignant tumors (51-55). Especially solid malignant tumors including prostate $(56,57)$, breast $(58,59)$ and lung cancers $(60,61)$ are supposed to be angiogenesis-dependent as shown for hepatocellular carcinoma (62-64). Tumor progression of HCC is associated with angiogenesis and the increase in microvascular density is associated with a poor prognosis. The inhibition of tumor angiogenesis and its complete comprehension is the aim when developing a successful anti-angiogenic tumor therapy. Angiogenesis is the formation and growth of new blood vessels from the already existing vasculature. It is necessary for various inflammatory, ischemic, infectious and immune disorders and also for malignant processes $(65,66)$.

Malignant cells are able to secrete pro-angiogenic factors including VEGF, which induces tumor blood vessel formation (67). The in vivo angiogenic activity of secreted VEGF may be regulated by extracellular inhibitors, because it is also produced in avascular tissues such as the cartilage. CTGF can inhibit VEGF-induced angiogenesis via complex formation of VEGF with CTGF through a protein-to protein interaction $(68,69)$. On the other hand, CTGF expresses mitogenic activity in endothelial cells to promote angiogenesis, although the potency of angiogenic activity of CTGF is not well-evaluated $(70,71)$. 
In conclusion, panobinostat induces differential expression of CTGF in a context-dependent manner. In this setting, the anti-angiogenesis is obviously not mediated via the classical VEGF-driven cascade.

Other pathways are supposed to be involved in the CTGF mediated angiogenesis and further experiments are necessary to explore the role of CTGF.

\section{Acknowledgements}

We thank Gabriele Krumholz for her great support in animal care and experiments. The excellent technical assistance of Astrid Taut and IsabelZeitträger is gratefully acknowledged. We also thank Professor Margarete Goppelt-Strübe (Department of Medicine 4, University Hospital Erlangen, Erlangen, Germany) for her support. Susanne Gahr was supported by the IZKF (Interdisziplinäres Zentrum für Klinische Forschung der Universität Erlangen-Nürnberg). Pietro Di Fazio is a Dame Sheila Sherlock-Fellow of the European Association for the Study of the Liver (EASL). Matthias Ocker received a research grant of the University Medical Center Giessen and Marburg (UKGM). The study was supported by the Novartis Pharma AG, Nuremberg, Germany.

\section{References}

1. Lodato F, Mazzella G, Festi D, Azzaroli F, Colecchia A and Roda E: Hepatocellular carcinoma prevention: A worldwide emergence between the opulence of developed countries and the economic constraints of developing nations. World $\mathrm{J}$ Gastroenterol 12: 7239-7249, 2006.

2. Bosch FX, Ribes J, Díaz M and Cléries R: Primary liver cancer: Worldwide incidence and trends. Gastroenterology 127 (Suppl 1): S5-S16, 2004.

3. Peto J: Cancer epidemiology in the last century and the next decade. Nature 411: 390-395, 2001.

4. Siegel R, Ma J, Zou Z and Jemal A: Cancer statistics, 2014. CA Cancer J Clin 64: 9-29, 2014

5. Duffy A and Greten T: Developing better treatments in hepatocellular carcinoma. Expert Rev Gastroenterol Hepatol 4: $551-560,2010$.

6. Omata M, Tateishi R, Yoshida H and Shiina S: Treatment of hepatocellular carcinoma by percutaneous tumor ablation methods: Ethanol injection therapy and radiofrequency ablation. Gastroenterology 127 (Suppl 1): S159-S166, 2004.

7. Llovet JM, Ricci S, Mazzaferro V, Hilgard P, Gane E, Blanc JF, de Oliveira AC, Santoro A, Raoul JL, Forner A, et al; SHARP Investigators Study Group: Sorafenib in advanced hepatocellular carcinoma. N Engl J Med 359: 378-390, 2008.

8. Okamoto K, Neureiter D and Ocker M: Biomarkers for novel targeted therapies of hepatocellular carcinoma. Histol Histopathol 24: 493-502, 2009.

9. Chan SL, Mok T and Ma BB: Management of hepatocellular carcinoma: Beyond sorafenib. Curr Oncol Rep 14: 257-266, 2012

10. Hanahan D and Weinberg RA: Hallmarks of cancer: The next generation. Cell 144: 646-674, 2011.

11. Sakurai T and Kudo M: Signaling pathways governing tumor angiogenesis. Oncology 81 (Suppl 1): 24-29, 2011.

12. Weis SM and Cheresh DA: Tumor angiogenesis: Molecular pathways and therapeutic targets. Nat Med 17: 1359-1370, 2011.

13. Ichihara $E$, Kiura $K$ and Tanimoto $M$ : Targeting angiogenesis in cancer therapy. Acta Med Okayama 65: 353-362, 2011.

14. Hicklin DJ and Ellis LM: Role of the vascular endothelial growth factor pathway in tumor growth and angiogenesis. J Clin Oncol 23: 1011-1027, 2005.

15. Chung AS, Lee J and Ferrara N: Targeting the tumour vasculature: Insights from physiological angiogenesis. Nat Rev Cancer 10: 505-514, 2010.

16. Shibuya M: Vascular endothelial growth factor-dependent and -independent regulation of angiogenesis. BMB Rep 41: 278-286, 2008 .
17. Veeravagu A, Hsu AR, Cai W, Hou LC, Tse VC and Chen X: Vascular endothelial growth factor and vascular endothelial growth factor receptor inhibitors as anti-angiogenic agents in cancer therapy. Recent Patents Anticancer Drug Discov 2: 59-71, 2007.

18. Amaoka N, Saio M, Nonaka K, Imai H, Tomita H, Sakashita F, Takahashi T, Sugiyama Y, Takami T and Adachi Y: Expression of vascular endothelial growth factor receptors is closely related to the histological grade of hepatocellular carcinoma. Oncol Rep 16: 3-10, 2006.

19. Kanno S, Oda N, Abe M, Terai Y, Ito M, Shitara K, Tabayashi K, Shibuya $M$ and Sato Y: Roles of two VEGF receptors, Flt-1 and $\mathrm{KDR}$, in the signal transduction of VEGF effects in human vascular endothelial cells. Oncogene 19: 2138-2146, 2000.

20. Ferrara N, Gerber HP and LeCouter J: The biology of VEGF and its receptors. Nat Med 9: 669-676, 2003.

21. Schoenleber SJ, Kurtz DM, Talwalkar JA, Roberts LR and Gores GJ: Prognostic role of vascular endothelial growth factor in hepatocellular carcinoma: Systematic review and meta-analysis. Br J Cancer 100: 1385-1392, 2009.

22. Sato Y, Kanno S, Oda N, Abe M, Ito M, Shitara K and Shibuya M: Properties of two VEGF receptors, Flt-1 and KDR, in signal transduction. Ann NY Acad Sci 902: 201-207, 2000.

23. Greten TF, Korangy F, Manns MP and Malek NP: Molecular therapy for the treatment of hepatocellular carcinoma. Br J Cancer 100: 19-23, 2009.

24. Carr BI, Carroll S, Muszbek N and Gondek K: Economic evaluation of sorafenib in unresectable hepatocellular carcinoma. J Gastroenterol Hepatol 25: 1739-1746, 2010.

25. Connock M, Round J, Bayliss S, Tubeuf S, Greenheld W and Moore D: Sorafenib for the treatment of advanced hepatocellular carcinoma. Health Technol Assess 14 (Suppl 1): 17-21, 2010.

26. Bergers $\mathrm{G}$ and Benjamin LE: Tumorigenesis and the angiogenic switch. Nat Rev Cancer 3: 401-410, 2003.

27. Baeriswyl V and Christofori G: The angiogenic switch in carcinogenesis. Semin Cancer Biol 19: 329-337, 2009.

28. Bradham DM, Igarashi A, Potter RL and Grotendorst GR: Connective tissue growth factor: A cysteine-rich mitogen secreted by human vascular endothelial cells is related to the SRC-induced immediate early gene product CEF-10. J Cell Biol 114: 1285-1294, 1991.

29. Shimo T, Nakanishi T, Nishida T, Asano M, Kanyama M, Kuboki T, Tamatani T, Tezuka K, Takemura M, Matsumura T, et al: Connective tissue growth factor induces the proliferation, migration, and tube formation of vascular endothelial cells in vitro, and angiogenesis in vivo. J Biochem 126: 137-145, 1999.

30. Perbal B: NOV (nephroblastoma overexpressed) and the CCN family of genes: Structural and functional issues. Mol Pathol 54: $57-79,2001$.

31. Li MH, Sanchez T, Pappalardo A, Lynch KR, Hla T and Ferrer F: Induction of antiproliferative connective tissue growth factor expression in Wilms' tumor cells by sphingosine-1-phosphate receptor 2. Mol Cancer Res 6: 1649-1656, 2008.

32. Hall-Glenn F, De Young RA, Huang BL, van Handel B, Hofmann JJ, Chen TT, Choi A, Ong JR, Benya PD, Mikkola H, et al: CCN2/connective tissue growth factor is essential for pericyte adhesion and endothelial basement membrane formation during angiogenesis. PLoS One 7: e30562, 2012.

33. Moussad EE and Brigstock DR: Connective tissue growth factor: What's in a name? Mol Genet Metab 71: 276-292, 2000.

34. Urtasun R, Latasa MU, Demartis MI, Balzani S, Goñi S, Garcia-Irigoyen O, Elizalde M, Azcona M, Pascale RM, Feo F, et al: Connective tissue growth factor autocriny in human hepatocellular carcinoma: Oncogenic role and regulation by epidermal growth factor receptor/yes-associated protein-mediated activation. Hepatology 54: 2149-2158, 2011

35. Wang GB, Zhou XY, Yuan T, Xie J, Guo LP, Gao N and Wang XQ: Significance of serum connective tissue growth factor in patients with hepatocellular carcinoma and relationship with angiogenesis. World J Surg 34: 2411-2417, 2010.

36. Hirasaki S, Koide N, Ujike K, Shinji T and Tsuji T: Expression of Nov, CYR61 and CTGF genes in human hepatocellular carcinoma. Hepatol Res 19: 294-305, 2001.

37. Zeng ZJ, Yang LY, Ding X and Wang W: Expressions of cysteine-rich61, connective tissue growth factor and Nov genes in hepatocellular carcinoma and their clinical significance. World J Gastroenterol 10: 3414-3418, 2004.

38. Xiu M, Liu YH, Brigstock DR, He FH, Zhang RJ and Gao RP: Connective tissue growth factor is overexpressed in human hepatocellular carcinoma and promotes cell invasion and growth. World J Gastroenterol 18: 7070-7078, 2012. 
39. Komorowsky C, Ocker M and Goppelt-Struebe M: Differential regulation of connective tissue growth factor in renal cells by histone deacetylase inhibitors. J Cell Mol Med 13: 2353-2364, 2009.

40. Schneider-Stock R and Ocker M: Epigenetic therapy in cancer: Molecular background and clinical development of histone deacetylase and DNA methyltransferase inhibitors. IDrugs 10: 557-561, 2007.

41. Di Fazio P, Schneider-Stock R, Neureiter D, Okamoto K, Wissniowski T, Gahr S, Quint K, Meissnitzer M, Alinger B, Montalbano R, et al: The pan-deacetylase inhibitor panobinostat inhibits growth of hepatocellular carcinoma models by alternative pathways of apoptosis. Cell Oncol 32: 285-300, 2010.

42. Lachenmayer A, Toffanin S, Cabellos L, Alsinet C, Hoshida Y, Villanueva A, Minguez B, Tsai HW, Ward SC, Thung S, et al: Combination therapy for hepatocellular carcinoma: Additive preclinical efficacy of the HDAC inhibitor panobinostat with sorafenib. J Hepatol 56: 1343-1350, 2012.

43. Gahr S, Wissniowski T, Zopf S, Strobel D, Pustowka A and Ocker M: Combination of the deacetylase inhibitor panobinostat and the multi-kinase inhibitor sorafenib for the treatment of metastatic hepatocellular carcinoma - review of the underlying molecular mechanisms and first case report. J Cancer 3: 158-165, 2012.

44. Di Fazio P, Montalbano R, Neureiter D, Alinger B, Schmidt A, Merkel AL, Quint K and Ocker M: Downregulation of HMGA2 by the pan-deacetylase inhibitor panobinostat is dependent on hsa-let-7b expression in liver cancer cell lines. Exp Cell Res 318 1832-1843, 2012.

45. Qian DZ, Kato Y, Shabbeer S, Wei Y, Verheul HM, Salumbides B, Sanni T, Atadja P and Pili R: Targeting tumor angiogenesis with histone deacetylase inhibitors: The hydroxamic acid derivative LBH589. Clin Cancer Res 12: 634-642, 2006.

46. Ocker M: Deacetylase inhibitors - focus on non-histone targets and effects. World J Biol Chem 1: 55-61, 2010.

47. Ellis L, Hammers $\mathrm{H}$ and Pili R: Targeting tumor angiogenesis with histone deacetylase inhibitors. Cancer Lett 280: 145-153, 2009.

48. Livak KJ and Schmittgen TD: Analysis of relative gene expression data using real-time quantitative PCR and the 2(-Delta Delta C(T)) method. Methods 25: 402-408, 2001.

49. Zuehlke J, Ebenau A, Krueger B and Goppelt-Struebe M: Vectorial secretion of CTGF as a cell-type specific response to LPA and TGF- $\beta$ in human tubular epithelial cells. Cell Commun Signal 10: 25, 2012.

50. Saif MW: Anti-VEGF agents in metastatic colorectal cancer (mCRC): Are they all alike? Cancer Manag Res 5: 103-115, 2013.

51. Gahr S, Peter G, Wissniowski TT, Hahn EG, Herold C and Ocker M: The histone-deacetylase inhibitor MS-275 and the CDK-inhibitor CYC-202 promote anti-tumor effects in hepatoma cell lines. Oncol Rep 20: 1249-1256, 2008.

52. Gahr S, Ocker M, Ganslmayer M, Zopf S, Okamoto K, Hartl A, Leitner S, Hahn EG and Herold C: The combination of the histone-deacetylase inhibitor trichostatin A and gemcitabine induces inhibition of proliferation and increased apoptosis in pancreatic carcinoma cells. Int J Oncol 31: 567-576, 2007.

53. Budman DR, Tai J, Calabro A and John V: The histone deacetylase inhibitor panobinostat demonstrates marked synergy with conventional chemotherapeutic agents in human ovarian cancer cell lines. Invest New Drugs 29: 1224-1229, 2011.

54. Neri P, Bahlis NJ and Lonial S: Panobinostat for the treatment of multiple myeloma. Expert Opin Investig Drugs 21: 733-747, 2012.
55. Simmons JK, Patel J, Michalowski A, Zhang S, Wei BR, Sullivan P, Gamache B, Felsenstein K, Kuehl WM, Simpson RM: TORC1 and class I HDAC inhibitors synergize to suppress mature B cell neoplasms. Mol Oncol 8: 261-272, 2014.

56. Antonarakis ES and Carducci MA: Targeting angiogenesis for the treatment of prostate cancer. Expert Opin Ther Targets 16: 365-376, 2012.

57. Schweizer MT and Carducci MA: From bevacizumab to tasquinimod: angiogenesis as a therapeutic target in prostate cancer. Cancer J 19: 99-106, 2013.

58. Liu TJ, Sun BC, Zhao XL, Zhao XM, Sun T, Gu Q, Yao Z, Dong XY, Zhao N and Liu N: CD133+ cells with cancer stem cell characteristics associates with vasculogenic mimicry in triplenegative breast cancer. Oncogene 32: 544-553, 2013.

59. Zhang Y, Hong H, Nayak TR, Valdovinos HF, Myklejord DV, Theuer CP, Barnhart TE and Cai W: Imaging tumor angiogenesis in breast cancer experimental lung metastasis with positron emission tomography, near-infrared fluorescence, and bioluminescence. Angiogenesis 16: 663-674, 2013.

60. Aggarwal C, Somaiah N and Simon G: Antiangiogenic agents in the management of non-small cell lung cancer: Where do we stand now and where are we headed? Cancer Biol Ther 13: 247-263, 2012.

61. Xiao YY, Zhan P, Yuan DM, Liu HB, Lv TF, Song Y and Shi Y: Chemotherapy plus multitargeted antiangiogenic tyrosine kinase inhibitors or chemotherapy alone in advanced NSCLC: A meta-analysis of randomized controlled trials. Eur J Clin Pharmacol 69: 151-159, 2013.

62. Pang R, Tse E and Poon RT: Molecular pathways in hepatocellular carcinoma. Cancer Lett 240: 157-169, 2006.

63. Ribatti D, Vacca A, Nico B, Sansonno D and Dammacco F: Angiogenesis and anti-angiogenesis in hepatocellular carcinoma. Cancer Treat Rev 32: 437-444, 2006.

64. Zhang Q, Du Y, Xue Z, Chi C, Jia X and Tian J: Comprehensive evaluation of the anti-angiogenic and anti-neoplastic effects of Endostar on liver cancer through optical molecular imaging. PLoS One 9: e85559, 2014.

65. Carmeliet P: Angiogenesis in life, disease and medicine. Nature 438: 932-936, 2005

66. Fischer C, Schneider M and Carmeliet P: Principles and therapeutic implications of angiogenesis, vasculogenesis and arteriogenesis. Handb Exp Pharmacol 176: 157-212, 2006.

67. Lin EY and Pollard JW: Tumor-associated macrophages press the angiogenic switch in breast cancer. Cancer Res 67: 5064-5066, 2007.

68. Inoki I, Shiomi T, Hashimoto G, Enomoto H, Nakamura H, Makino K, Ikeda E, Takata S, Kobayashi K and Okada Y: Connective tissue growth factor binds vascular endothelial grow th factor (VEGF) and inhibits VEGF-induced angiogenesis. FASEB J 16: 219-221, 2002

69. Hashimoto G, Inoki I, Fujii Y, Aoki T, Ikeda E and Okada Y: Matrix metalloproteinases cleave connective tissue growth factor and reactivate angiogenic activity of vascular endothelial growth factor 165. J Biol Chem 277: 36288-36295, 2002

70. ShimoT, Nakanishi T, Kimura Y,Nishida T, IshizekiK, MatsumuraT and Takigawa M: Inhibition of endogenous expression of connective tissue growth factor by its antisense oligonucleotide and antisense RNA suppresses proliferation and migration of vascular endothelial cells. J Biochem 124: 130-140, 1998.

71. Babic AM, Chen CC and Lau LF: Fisp12/mouse connective tissue growth factor mediates endothelial cell adhesion and migration through integrin alphavbeta3, promotes endothelial cell survival, and induces angiogenesis in vivo. Mol Cell Biol 19: 2958-2966, 1999. 